Article

\title{
Fuzzy Based Risk Assessment for Decommissioning Concrete Bioshield Structures in Nuclear Power Plants: Structural Risks and Worker Safety
}

\author{
Byeol Kim ${ }^{1} \mathbb{D}$, Joo sung Lee ${ }^{2, * \mathbb{C}}$ and Yong han Ahn ${ }^{3, *}$ \\ 1 Department of Architectural Engineering, Hanyang University, 55 Hanyangdaehak-ro, Sangrok-gu, \\ Ansan-si, Gyeonggi-do 15588, Korea \\ 2 Innovative Durable Building and Infrastructure Research Center, Hanyang University, \\ 55 Hanyangdaehak-ro, Sangrok-gu, Ansan-si, Gyeonggi-do 15588, Korea \\ 3 School of Architecture and Architectural Engineering, Hanyang University, 55 Hanyangdaehak-ro, \\ Sangrok-gu, Ansan-si, Gyeonggi-do 15588, Korea \\ * Correspondence: js4ever@hanyang.ac.kr (J.s.L.); yhahn@hanyang.ac.kr (Y.h.A.); \\ Tel.: +82-31-436-8182 (Y.h.A.)
}

Received: 5 March 2020; Accepted: 8 April 2020; Published: 10 April 2020

\begin{abstract}
Few studies have assessed the safety issues involved in decommissioning nuclear facilities, especially from a structural and job perspective; in most developed countries, the focus is generally on the radiological risks. This study highlights the inadequacy of existing deterministic risk assessment methods, which cannot account for the uncertainty and complexity of hazards that workers are exposed to. We instead propose a fuzzy logic based safety assessment model that can analyze and compare alternatives utilizing a step-by-step risk quantification and multidimensional approach. This enables personnel to assess the various risks involved when decontaminating and decommissioning nuclear power plant structures that cannot be quantitatively assessed owing to a lack of data. Our proposed fuzzy based risk assessment model can also be applied to risk assessment in other engineering fields that depend on the judgment of experts supported by little or no statistical data.
\end{abstract}

Keywords: decommissioning worker risk assessment; fuzzy based safety assessment; in-depth interview; decommissioning work package of nuclear power plant; structural and job damage

\section{Introduction}

Of the 438 nuclear power plants in operation worldwide, 224 have been operating for more than 30 years. Now that over half our nuclear power plants have reached this milestone, we are officially in the aging stage of this technology [1]. In particular, for old nuclear power plants operating for more than 30 years, decisions on decommissioning can be made at any time for political and economic reasons. It therefore seems likely that nuclear power plant decommissioning projects will be carried out in many of the countries using nuclear power over the next 20 to 30 years.

The primary objective of a decommissioning plan is the removal of the radiological and non-radiological hazards associated with the operation of a nuclear facility or system. This not only allows the facility to be released from regulatory control but also protects the workers, the general public, and the environment during the process [2]. The International Atomic Energy Agency (IAEA) defines "decommissioning" as removing the inherent functions of a nuclear facility while ensuring the health and safety of workers, the general public and protecting the environment, as well as all actions taken at the end of the life cycle of the nuclear facility [3]. The process of decommissioning nuclear facilities can be largely divided into three stages: preliminary preparation, decommissioning, and post-recovery. In the preliminary preparation stage, it is necessary to determine the decommissioning project's 
goals, strategies, the feasibility of technology development, and the amount of funding required, as well as to evaluate the characteristics of the facilities and the site. The decommissioning stage involves decontamination, cutting, demolition, and radioactive waste management. In the final post-recovery stage, the site is restored, and site regulations are addressed. A nuclear decommissioning project is long-term and requires a minimum of several years to perform these tasks, with a total of 38 core infrastructure technologies needed. Before decommissioning, proper planning, assessment, and verification are needed to safely and successfully implement these technology-intensive decommissioning projects $[4,5]$. In the decommissioning planning stage, it is vital to establish proper decommissioning procedures and to conduct a comprehensive assessment of the safety of the decommissioning process in order to select the optimal decommissioning process scenario. In particular, when decommissioning radioactive areas, the processes to be used and their safety should be assessed in advance to derive an optimal decommissioning process, thereby improving worker safety and decommissioning efficiency $[6,7]$.

Currently, most of the safety assessments that have been performed for nuclear power plant decommissioning projects in developed countries have focused on the radiological risks involved [8]. According to the completion reports submitted for projects decommissioning nuclear power facilities in developed countries, the types of accidents that cause harm to workers during decommissioning are also associated with other hazards including occupational exposure, fires and explosions, handling of hazardous materials, and physical and electrical hazards [1,9]. Radiological, physical, and chemical hazards account for $67.2 \%, 17.6 \%$, and $14.8 \%$, respectively, of the hazards encountered during decommissioning. Thus, both radiological and non-radiological hazards need to be considered when decommissioning nuclear facilities [2]. In order to protect workers and prevent accidents during the decommissioning of nuclear facilities, a proper decommissioning plan should thus be established that takes into account both radiological and non-radiological hazards. As nuclear decommissioning involves working close to radioactive structures, a risk management approach is needed to avoid both structural and job risks. The objective of this study was therefore to develop a structural risk assessment model that is suitable for both the decontamination and decommissioning of nuclear power plants. In general, the frequency and intensity of risks are considered in the assessment of risks. The frequency of risk can be recognized as an event in which a risk has occurred, and the intensity of risk can be given meaning as a depth of risk. This is assessed based on expert experience or judgment. The fuzzy theory proposed by Zadeh (1965) has been applied to logically and scientifically reflect the uncertainty, ambiguity, and subjectivity of the analyst in risk assessment. Therefore, this study aims to quantify risk and systematically analyze the profile of possible risks [10].

\section{Literature Review}

Nuclear power plants necessarily include features that must be treated with great caution from a safety perspective because radioactive materials are generated during the energy generation process. Thus, for the safe management of nuclear power plants, various risk management models have been proposed (Table 1). For early nuclear power plants, a deterministic approach was used as the only safety assessment criterion in the design and operation phases [11]. However, deterministic risk management techniques are relatively inflexible and tend to present a fixed value regardless of project conditions, period, geographical features, size, and type of facility. 
Table 1. The most frequently used applications of risk-related techniques in nuclear power plant field.

\begin{tabular}{|c|c|c|c|}
\hline Technique & Aim & Main Limitation & Reference \\
\hline $\begin{array}{l}\text { The advanced } \\
\text { deterministic approach }\end{array}$ & $\begin{array}{l}\text { Quantify risk through conservative } \\
\text { calculations that included } \\
\text { boundary assumptions }\end{array}$ & $\begin{array}{ll}- & \text { Present a fixed value } \\
\text { - } & \text { It is difficult to respond } \\
\text { to accidents }\end{array}$ & {$[11,12]$} \\
\hline Fault tree analysis (FTA) & $\begin{array}{l}\text { Quantitatively assessing the safety of } \\
\text { both equipment and systems by } \\
\text { analyzing the underlying causes } \\
\text { of accidents }\end{array}$ & 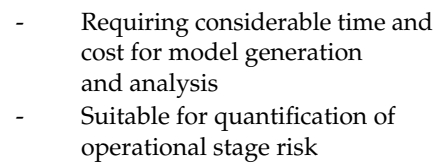 & [13-15] \\
\hline Event tree analysis (ETA) & $\begin{array}{l}\text { Inductive analysis of safety through } \\
\text { expression of chain form from initial } \\
\text { events to accidents }\end{array}$ & $\begin{array}{l}\text { Real situations require detailed } \\
\text { explanations that involve the } \\
\text { creation of large event trees }\end{array}$ & [16-18] \\
\hline The Bayesian approach & $\begin{array}{l}\text { Statistical analysis based on the } \\
\text { assumption that mathematics } \\
\text { subjective probability is actually } \\
\text { possible in uncertain situations }\end{array}$ & $\begin{array}{l}\text { Various problems can occur } \\
\text { when applied to } \\
\text { actual problems. }\end{array}$ & [19-21] \\
\hline $\begin{array}{l}\text { The Dempster-Shafer } \\
\text { (D-S) approach }\end{array}$ & $\begin{array}{l}\text { Statistical analysis dealing with } \\
\text { uncertainty that does not fit the } \\
\text { probability of the Bayesian rule }\end{array}$ & $\begin{array}{l}\text { Data or evidence observed from } \\
\text { multiple sources may involve } \\
\text { unavoidable biases or errors due } \\
\text { to measurement errors and } \\
\text { human factors. }\end{array}$ & [22-25] \\
\hline Fuzzy inference approach & $\begin{array}{l}\text { Quantify ambiguity that is accepted } \\
\text { as consecutive values between } 0 \text { and } 1\end{array}$ & $\begin{array}{l}\text { - It is difficult to accurately } \\
\text { estimate the degree } \\
\text { of uncertainty. }\end{array}$ & {$[2,26,27]$} \\
\hline
\end{tabular}

Since the mid-70s, many studies have been conducted that attempt to compensate for the uncertainties in conservative evaluation models, with most of the resulting models attempting to quantify risk through conservative calculations that included boundary assumptions. For example, Boyack et al. (1989) applied an approach they called code scaling, applicability, and uncertainty to calculate peak cladding temperatures. The introduction of the best estimate plus uncertainty methodology made it possible to predict realistic safety margins, while at the same time retaining the deterministic approach concept [11]. However, if safety management is performed in this way, it is difficult to respond to accidents. Risk management based on risk assessment should include steps that can be taken to prevent accidents and mitigate the impact in the event of an accident. To do this, it is important to present anticipated accident scenarios following a logical process that makes it possible to calculate their probability and impact, preventing and mitigating accidents and assessing the associated risks quantitatively.

Because the accuracy and reliability of this analysis is necessarily expressed in probabilities, a probabilistic approach is more conducive to risk management than a deterministic approach from the perspective of uncertainty. Thus, ever since the 1970s, fault tree analysis, a popular probabilistic hazard analysis method, has become commonplace $[13,14]$. This provides a method of quantitatively assessing the safety of both equipment and systems by analyzing the underlying causes of accidents, such as faulty facilities or human error, deductively, sequentially, schematically and stochastically. An FTA-based risk monitor is now the most widely used method for conducting reliability and risk analyses as it identifies necessary measures that must be taken in the early stages of a disaster, allowing the effective correction of faults in complex systems with minimum time and cost [15]. However, this is a very complex process and often results in a large number of defects, requiring considerable time and cost for model generation and analysis. Therefore, a new inductive analytical method known as an event tree analysis has been proposed to verify the defect event following an initial event [16]. Using ETA techniques, computerization and scenario development for the types of defects that could occur can provide useful information. However, most real situations require detailed explanations that involve the creation of large event trees that take a long time to analyze. To reduce the size of these 
trees, researchers have suggested ways to simplify the converted fault tree within the event tree $[17,18]$. The resulting risk monitoring system, dubbed Risk Angel, was developed to demonstrate the effect of reducing the risk calculation time.

However, nuclear energy-related operations are inherently more uncertain and involve more risk factors than other industries, so optimizing a model takes a lot of time and money. Moreover, there is a lack of mathematical data of the type required for the analysis. There are ways to deal with this uncertainty such as the Bayesian approach, the Dempster-Shafer(D-S) approach and fuzzy inference approach. The Bayesian theory is theoretically organized. However, the application of this method requires knowledge of the prior probability and likelihood probability. Therefore, this approach is useful for troubleshooting areas where probabilistic estimates are easy or not complex [21]. The D-S theory is intended to extend uncertainty to segments including the degree of likelihood without limiting the axiom of probability theory [24]. However, all the terminology used in knowledge is handled independently. There is no distinction between uncertainty due to the incompleteness of knowledge and uncertainty due to the ambiguity of the predicate itself used for knowledge.

Fuzzy theory is used to solve these problems [2]. The Bayesian theory and the D-S theory represent various estimates numerically. Fuzzy theory, on the other hand, presents these estimates in the form of distributions, which are useful because they are chosen and used according to the analyst's intuition. However, even if the form of the membership function use is flexibly set, the usefulness of deriving meaningful outcomes may be limited if the fuzzy rules are not properly constructed. In previous research, this fuzzy application was limited to managing the risks associated with the construction and operation phases of nuclear power plant projects. Since the decommissioning phase must take into account radiological risks in addition to the non-radiological risks that appear in construction work, verification is required through research to confirm the applicability of safety assessment methodologies based on fuzzy logic. To address this issue, Jeong et al. (2010) applied a risk assessment model that incorporates the risk matrix concept and fuzzy theory to conduct a risk assessment of the KRR-2 decommissioning project. This demonstrated that the proposed methodology is useful as a quantitative risk assessment tool for the safe decommissioning of nuclear facilities. However, this study focused primarily on applying fuzzy theory to determine the safety management priorities for the decommissioning project. The characteristics of the work carried out on the site (working processes, utilization of equipment, location of work, etc.) were not considered systematically, rendering its use as a risk assessment tool for the actual fieldwork required during the decommissioning project as insufficient. The study reported here therefore builds on this earlier work by extending the fuzzy analysis method developed by Jeong et al. (2010) to analyze in detail and quantify the various risk profiles that occur during the decommissioning phase for a nuclear power plant.

\section{Methodology}

This study sought to develop a process for evaluating the structural and job risks involved in the nuclear decommissioning process using the fuzzy theory proposed by Zadeh (1965). For this purpose, we divided the research into three stages, namely (1) risk identification, (2) data collection, and (3) conduct measurement (Figure 1).

\begin{tabular}{|c|c|}
\hline STEP 1. Risk identification & $\begin{array}{r}\text { Derive structural and job risks process through a matching process based on the } \\
\text { similarity between construction work and decontamination and decommissioning work }\end{array}$ \\
\hline STEP 2. Data collection & Configure validation working group \\
\hline STEP 3. Conduct measurement & Risk assessment modeling $\rightarrow$ Expert interviews $\rightarrow$ Risk assessment \\
\hline
\end{tabular}

Figure 1. Flow of research methodology. 
The case study for the risk assessment methodology developed from the results of this study is the Kori-1 nuclear power plant. This is the Korea's first commercial nuclear power plant and type is pressurized-water reactor type. The facility was shut down on June 19, 2017, after 39 years of commercial operation, and decommissioning is currently in progress.

For this study, a risk assessment was carried out for the shield concrete structure as this suffers the greatest number of structural and job-related accidents within the entire nuclear power plant decontamination and decommissioning process. The technological methods utilized to perform concrete decommissioning generally include cutting and crushing; in this case, a diamond wire saw was used for cutting up the concrete, to alleviate public concerns.

Step 1. Risk identification:

Figure 2 shows a flow chart of the structural and job risks associated with each process using a matching process based on similarities between construction and decontamination and decommissioning operations. The risk list was created by considering the characteristics of construction and decontamination and decommissioning, and the risks matched for each process based on those potentially encountered during the decontamination and decommissioning of a nuclear reactor concrete structure. These were identified in previous studies, including a case study that described the decommissioning and demolition of a research nuclear reactor and the development of a work breakdown structure (WBS) for reactor decommissioning and demolition [28].

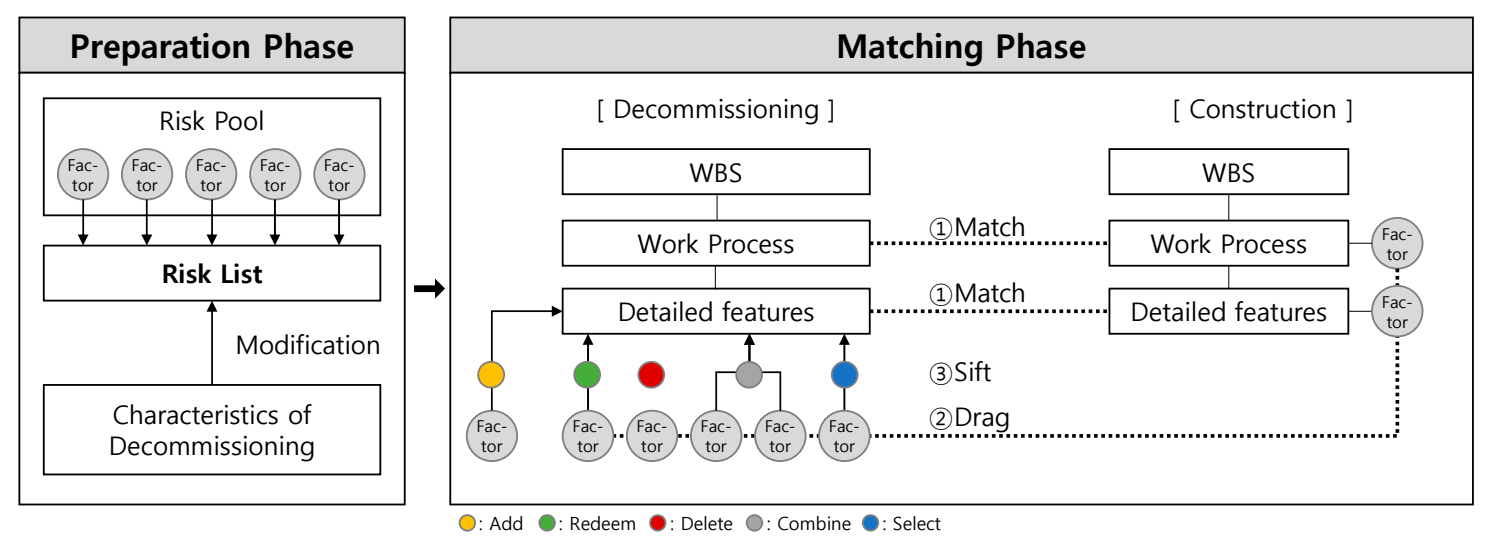

Figure 2. Risk identification step process.

Step 1.1. Preparation Phase:

Unlike existing risk assessment methods, this study classified the risks for each process in terms of the work type, structural risks, and job risks (Tables 2 and 3). The risk list was created based on the construction risks identified in the OSHA standard, which is widely used in the construction industry [29]. In addition, to account for the special characteristics of the decontamination and decommissioning process for nuclear facilities, we consolidated/added/deleted risk items by considering the risks presented by the IAEA to create the final risk list [30].

Table 2. Work hazards.

\begin{tabular}{cl}
\hline \multicolumn{1}{c}{ Classification } & \multicolumn{1}{c}{ Hazards } \\
\hline & $\begin{array}{l}\text { Falls, trench collapse, scaffold collapse, electric shock } \\
\text { and arc flash/arc blast, failure to use proper personal } \\
\text { protective equipment, repetitive motion injuries }\end{array}$ \\
Example of a checklist of hazards [30] & $\begin{array}{l}\text { Fire, explosion, flooding, toxic and hazardous } \\
\text { materials, electrical hazards, physical hazards, } \\
\text { human and organizational initiating events }\end{array}$ \\
\hline
\end{tabular}


Table 3. Structural and job risks associated with decommissioning a bio-shield structure.

\begin{tabular}{ccl}
\hline Risk & Item & \multicolumn{1}{c}{ Description } \\
\hline Structural risks & Collapse & $\begin{array}{l}\text { Structures or temporary objects (equipment, machines, } \\
\text { scaffolds, etc.) fall over or collapse } \\
\text { Decommissioned or temporary objects (equipment, machines, } \\
\text { scaffolds, etc.) drop from a high platform to a low platform }\end{array}$ \\
\hline Job risks & Fall & $\begin{array}{l}\text { Victim's eyes are exposed to dust and similar materials } \\
\text { Worker falls from a high platform such as a structure, } \\
\text { temporary structure, or ladder }\end{array}$ \\
& Jam & $\begin{array}{l}\text { Worker is caught between moving objects, or twisted or } \\
\text { pierced by a rolling body or protrusion } \\
\text { Current flows through a worker's body }\end{array}$ \\
\hline
\end{tabular}

We derived the most problematic structural and job risks in order to use the developed risk assessment methodology to establish a decommissioning process plan in accordance with the ALARA principle (As Low As Reasonably Achievable) [31]. Here, structural risks refer to potential damage to the structure itself due to various hazards encountered during decontamination and decommissioning, as well as damage to temporary structures or the heavy equipment used in decommissioning, while job risks refer to direct physical injuries experienced by workers on the site due to disasters and accidents.

\section{Step 1.2. Matching Phase:}

Decontamination and decommissioning of the shield structure of the nuclear power plant can be considered a specific type of decommissioning and demolition operation within the construction process, hence the same standards can be applied. We therefore matched the main work tasks and their characteristics based on the similarities between decontamination and decommissioning and construction to derive the risks. This type of risk derivation and assessment system that takes into account site characteristics can be utilized as a tool for preliminary inspections of actual sites [32,33].

First, in order to identify and specify appropriate risks for the decontamination and decommissioning processes for the concrete shield structure of the nuclear power plant, we listed the decontamination and decommissioning processes involved and their possible risks by work type. This consisted of three levels: work type (Level 1), work content (Level 2), and work details (Level 3). Level 1 includes the main tasks that are performed for each step, Level 2 describes the types of risks associated with each of these main tasks, and Level 3 provides detailed descriptions of the tasks performed (work location/work object/work equipment) for each item listed in Level 2. According to a report by the US Department of Energy (DOE, 1998), structural risk management is vital in the decontamination and decommissioning of nuclear power plants, as the activities involved have similar characteristics to the original construction process. Therefore, possible structural and job risks were derived for each process based on the similarities between construction and decontamination and decommissioning for this study, focusing on the structural and decommissioning job risks that may arise during the direct decommissioning of shield structures. The example shown in Table 4 presents details of the cutting processes involved in: (1) the site preparation; (2) the decontamination process; (3) the various drilling and cutting demolition activities; and (4) the equipment transportation and the removal of the decontamination and decommissioning products, based on the decommissioning work breakdown structure of the TRIGA Mark-III reactor, which was decommissioned in 2005 following the guidelines provided in the IAEA's nuclear power plant decommissioning package (IAEA, 1999). The process is divided into wire saw installation, cutting, and residual concrete removal, which are further divided into four tasks. 
Table 4. Cutting process.

\begin{tabular}{|c|c|c|c|c|c|c|c|}
\hline \multirow{2}{*}{$\begin{array}{c}\text { Level } 1 \\
\text { Work Type }\end{array}$} & \multirow{2}{*}{\multicolumn{2}{|c|}{$\begin{array}{c}\text { Level } 2 \\
\text { Work Content }\end{array}$}} & \multicolumn{5}{|c|}{ Level 3} \\
\hline & & & Work & tail ${ }^{a}$ & Work Location & Work Object & Work Equipment \\
\hline \multirow{4}{*}{ Cutting work } & \multirow[t]{2}{*}{1.1} & \multirow[t]{2}{*}{ Wire saw installation } & 1.1.1 & $\mathrm{Wt}$ & $\begin{array}{l}\text { Low elevation, } \\
\text { high elevation }\end{array}$ & Wire saw & Transport equipment \\
\hline & & & 1.1 .2 & Wi & $\begin{array}{l}\text { Low elevation, } \\
\text { high elevation }\end{array}$ & Wire saw & Installation tool \\
\hline & 1.2 & Cutting using wire saw & 1.2 .1 & $\mathrm{Cw}$ & $\begin{array}{l}\text { Low elevation, } \\
\text { high elevation }\end{array}$ & Shield structure & Wire saw \\
\hline & 1.3 & Remove residual concrete & 1.3.1 & Rc & $\begin{array}{l}\text { Low elevation, } \\
\text { high elevation }\end{array}$ & Shield structure & Brake, scabbler \\
\hline
\end{tabular}

${ }^{\mathrm{a}} \mathrm{Wt}=$ wire saw transport; $\mathrm{Wi}=$ wire saw installation; $\mathrm{CW}=$ cutting $\mathrm{using}$ wire saw; $\mathrm{Rc}=$ remove residual concrete.

We derived the risks for each decontamination and decommissioning process via the matching process described above (the Matching Phase in Figure 2) based on the construction industry hazard profile and the decontamination and decommissioning processes required by nuclear power plant shield concrete structures, configured above. The matching process proceeds as follows: (1) match similar main tasks between decontamination and decommissioning work and construction work; (2) match similar characteristics of the main tasks between construction work and decontamination and decommissioning work (work location/work object/work equipment); and (3) derive the risks associated with cutting activities in decontamination and decommissioning work, taking into account the unique features of decontamination and decommissioning work.

The step-by-step matching process proposed in this study is based on the information shown in Level 3 of Table 4. Welding, cutting, and felling were matched as the main tasks of construction work associated with cutting activities, while mid-size backhoes, drillers, and earth augers were matched as similar pieces of equipment to the wire saws used in cutting. In addition, the work performed at the upper part of the reactor was matched to construction work involving high working platforms. Finally, all the matched construction work risk items are included in the risk pool for each detailed cutting task. For our purposes, it is important to select valid risks from the configured risk pool. For work with a unique trait that exists only in decontamination and decommissioning work or for which it is difficult to find similarities between decontamination and decommissioning work and construction work, the assessor must review the characteristics with a full understanding of the work and consideration of the site situation. Table 5 presents the risks that may occur in the detailed tasks of cutting that were finally derived through this process.

Table 5. Potential risks of the cutting phase.

\begin{tabular}{lcccccc}
\hline Work Type & & Work Content & \multicolumn{2}{c}{ Work Detail $^{\mathbf{a}}$} & Structural Risk $^{\mathbf{b}}$ & Job Risk $^{\mathbf{c}}$ \\
\hline \multirow{3}{*}{ Cutting work } & \multirow{2}{*}{ Wire saw installation } & 1.1 .1 & $\mathrm{Wt}$ & $\mathrm{Co}, \mathrm{Dr}$ & $\mathrm{Jam}$ \\
& 1.2 & Cutting using wire saw & 1.2 .1 & $\mathrm{Wi}$ & $\mathrm{Co}, \mathrm{Dr}$ & $\mathrm{Jam}, \mathrm{Es}$ \\
& 1.3 & Remove residual concrete & 1.3 .1 & $\mathrm{Rc}$ & $\mathrm{Co}, \mathrm{Dr}$ & $\mathrm{Ea}, \mathrm{jam}, \mathrm{Es}$ \\
& & $\mathrm{Co}$ & $\mathrm{Ea}, \mathrm{Fa}, \mathrm{jam}, \mathrm{Es}$ \\
\hline
\end{tabular}

${ }^{\mathrm{a}} \mathrm{Wt}=$ wire saw transport; $\mathrm{Wi}=$ wire saw installation; $\mathrm{Cw}=$ cutting using wire saw; $\mathrm{Rc}=$ remove residual concrete.

${ }^{\mathrm{b}} \mathrm{Co}=$ collapse; $\mathrm{Dr}=$ drop. ${ }^{\mathrm{c}} \mathrm{Ea}=$ eye attack; $\mathrm{Fa}=$ fall; Es = electric shock.

Step 2. Data collection:

It was not possible to conduct large-scale surveys due to the nature of this study; instead, we carried out in-depth interviews with experts with experience working on similar projects. This expert group (Table 6) consisted of workers and researchers from research and public institutions, general contractors, and specialty contractors, providing a wide-ranging risk assessment from the perspectives of many different stakeholders, all of whom were experts with extensive experience of nuclear power plant projects, thereby increasing reliability. The 12 experts completed questionnaires in a one-on-one environment after a clear understanding of the questionnaire. We also brought together experts from different fields to conduct group discussions and conducted individual in-depth interviews with all 
the study participants. Respondents completed email questionnaires after an initial phone contact and in-person live pre-interviews between September 7th and December 18th, 2018.

Table 6. Composition of the experts.

\begin{tabular}{cccc}
\hline Category & Item & Frequency & Percentage (\%) \\
\hline \multirow{4}{*}{ Experience } & < years & 2 & 16.7 \\
& $5-10$ years & 5 & 41.6 \\
& $10-15$ years & 2 & 16.7 \\
& $15-20$ years & 1 & 8.3 \\
\multirow{3}{*}{ Field } & $\geq 20$ years & 2 & 16.7 \\
& Research Institution & 1 & 8.3 \\
& Experts related to Construction Management & 2 & 16.7 \\
& Experts related to Structural Engineering & 2 & 16.7 \\
& General Contractor & 4 & 33.3 \\
& Specialty Contractor & 3 & 25 \\
& & 12 & 100 \\
\hline
\end{tabular}

As a result of an advisory meeting with safety experts, we assumed that the impact of the experts contribution to the assessment would be proportional to a benchmark 10 year-career experience level. [34,35]. Based on their career experience, their respective contributions to the assessment were therefore assigned as shown in Table 7. Thus, $C_{1}+C_{2}+\cdots+C_{m}=1$, where $C_{1}, C_{2}, \cdots, C_{m}$ are the contributions of expert ${ }_{1}$, expert $_{2}, \cdots$, expert ${ }_{m}$, respectively.

Table 7. Details of experts' contribution.

\begin{tabular}{ccccc}
\hline Expert & Field & Career Experience & Impact & Contribution $\left(C_{\boldsymbol{i}}\right)$ \\
\hline$C_{1}$ & Research Institution & 10 & 1 & 0.08 \\
$C_{2}$ & Experts related to Construction Management & 3 & 0.3 & 0.024 \\
$C_{3}$ & Experts related to Construction Management & 3 & 0.3 & 0.024 \\
$C_{4}$ & Experts related to Structural Engineering & 7 & 0.7 & 0.056 \\
$C_{5}$ & Experts related to Structural Engineering & 20 & 2 & 0.16 \\
$C_{6}$ & General Contractor & 28 & 2.8 & 0.224 \\
$C_{7}$ & General Contractor & 8 & 0.8 & 0.064 \\
$C_{8}$ & General Contractor & 5 & 0.5 & 0.04 \\
$C_{9}$ & General Contractor & 15 & 1.5 & 0.12 \\
$C_{10}$ & Specialty Contractor & 8 & 0.8 & 0.064 \\
$C_{11}$ & Specialty Contractor & 8 & 0.8 & 0.064 \\
$C_{12}$ & Specialty Contractor & 10 & 1 & 0.08 \\
Sum & & 125 & 12.5 & 1 \\
\hline
\end{tabular}

Step 3. Conduct measurement:

If the data required for stochastic or statistical assessment is uncertain, inaccurate, or incomplete, then the results of the assessment are unreliable [36,37]. In fields related to nuclear engineering, researchers have traditionally relied on data from previous studies or the engineering judgment of experts based on past experience. However, it is nearly impossible for an analyst to accurately, precisely, and objectively assess the subject of their analysis as the analyst's judgment is inevitably somewhat subjective and ambiguous [38]. Fuzzy inference-based methodologies have been widely used in various fields to address these disadvantages [39,40]. In particular, fuzzy inference methods can be very useful in situations where there is a lack of reliable empirical data, which is the case when attempting to assess the risks involved in the decontamination and decommissioning of nuclear facilities; this issue is made even worse due to the unclear correlation between the various radiological, non-radiological, and structural risks.

The risk assessment process based on the decontamination and decommissioning risk classification system derived above is performed in the following order: (1) risk assessment modeling, (2) expert interviews, and (3) risk assessment and analysis. The basic risk assessment concept of this study 
was based on the MIL-STD 882 standard [41]. In general, the frequency and intensity of risks are considered in the assessment of hazards, which are then divided into several levels [42]. For this study, the intensity and frequency of structural and job risks were each classified into five levels for use in the subsequent risk assessment. The worker risk was calculated by adding the intensity and frequency of job risks and the frequency weights by work of structural risks. Equation 1 gives the formula for the calculation of the total worker risk:

$$
H=\sum_{k=1}^{p} h_{k} \sum_{j=1}^{o} f_{j k} I_{j k}
$$

where $H$ is the total worker risk (expected rate of labor loss due to accidents during decommissioning work), $f_{j k}$ is the frequency of occurrence of risk $\mathrm{j}$ in work $\mathrm{k}, I_{j k}$ is the severity of risk $\mathrm{j}$ in work $\mathrm{k}$, and $h_{k}$ is the level of risk of work $k$ (weight).

The level of structural risk is defined as the height at which the accident can occur, and the level of job risk is defined as the rate of labor loss. The frequency of occurrence of the risk is expressed by the fuzzy function (see Tables 8-10). Collapse or fall is generally classified according to the height of the accident [43] and the UK's Health and Safety Executive categorizes fall-related accidents as either slip, trip or fall on the same level, or fall from a height [44]. In this study, the maximum height of the bio-shield, $12 \mathrm{~m}$, was classified into the following five categories [45]: very low impact (ground or same level falls), low impact (height of $2 \mathrm{~m}$ ), moderate (height of 2-5 m), high impact (height of 5-10 m), and very high impact (height of more than $10 \mathrm{~m}$ ). Job risk damage is generally classified into the disability evaluation shown in Table 9, where the evaluation method assesses the labor loss rate on a scale from $0 \%$ to $100 \%$ based on the type of disability, parts and occupations incurred [46]. The rate of labor loss is classified in terms of five levels, ranging from minor injuries $(1 \%)$, disorders such as lumbar compression fractures (25\%), disorders such as shoulder disarticulation (50\%), and serious disorders such as cutting arms (75\%) up to death $(100 \%)$.

Table 8. Structural risk damage definition and relative values.

\begin{tabular}{cccc}
\hline Item & Category & Damage Definition (by Accident Height) & Relative Value \\
\hline \multirow{4}{*}{$I_{j k}$} & Very high impact & Height of over $10 \mathrm{~m}$ & 10 \\
& High impact & Height of $5-0 \mathrm{~m}$ & 7.5 \\
& Moderate & Height of $2-5 \mathrm{~m}$ & 5 \\
& Low impact & Height of $2 \mathrm{~m}$ & 2.5 \\
& Very low impact & Occurs at the same level & 1 \\
\hline
\end{tabular}

Table 9. Job risk damage definition and relative values.

\begin{tabular}{cccc}
\hline Item & Category & Damage Definition (\%) & Relative Value \\
\hline \multirow{4}{*}{$I_{j k}$} & Very high impact & Death (100) & 10 \\
& High impact & Serious disorders such as cutting arms (75) & 7.5 \\
& Moderate & Disorders such as shoulder disarticulation (50) & 5 \\
& Low impact & Disorders such as lumbar compression fractures (25) & 2.5 \\
& Very low impact & Minor injury (1) & 1 \\
\hline
\end{tabular}

Table 10. Structural/job risk occurrence frequency fuzzy function.

\begin{tabular}{cccc}
\hline Item & Category & Occurrence & Fuzzy Function \\
\hline \multirow{4}{*}{$f_{j k}$} & Very high & $1: 1$ & $(7.5,10,10)$ \\
& High & $1: 0.75$ & $(5,7.5,10)$ \\
& Moderate & $1: 0.5$ & $(2.5,5,7.5)$ \\
& Low & $1: 0.25$ & $(0,2.5,5)$ \\
& Very low & $1: 0$ & $(0,0,2.5)$ \\
\hline
\end{tabular}


To assess possible structural and job risks using the detailed tasks (Level 3) for cutting derived above, we conducted a survey on risk frequency and intensity through in-depth interviews with 12 experts. The frequency decisions and probabilities were then reconverted through fuzzy integration and defuzzification of the assessment results.

The risks of the fuzzified decontamination and decommissioning process are quantitatively calculated as a single value for each task through a defuzzification process. Here, we used the centroid method, which is generally regarded as the most effective defuzzification technique and is thus extensively used for these types of calculations [7]. Equation 2 describes the defuzzification process using the centroid method [47].

$$
\text { risk score for each work }=\frac{\int \mu_{R}(x) \cdot x d x}{\int \mu_{R}(x) d x}
$$

where $\mathrm{x}$ is the risk score for each task and $\mu_{R}(x)$ is the membership function value of the risk for each task.

\section{Results}

We assessed the risks involved in each of the four tasks for the concrete cutting stage- - the main target of management within the shield concrete structure decontamination and decommissioning processes described above. We calculated the level of risk by work, structural risk, and job risk, as well as the total risk. Here, the risk is roughly estimated to be in the range of 0 to 100 , which indicates the minimum and maximum values when the frequency and depth are either at their lowest or highest. In addition, slight differences may occur depending on the weight; here, a larger number indicates greater risk.

Table 11 presents the risk assessment results for each task. The risk was assessed in terms of the structural and job risk items that could be generated for that type of work. We derived the converted value by assigning the weight for each task determined by the expert interview to the overall score. The assessment by work type revealed the levels of risk to be in the following order: residual concrete removal (54.17), cutting with wire saw (21.21), wire saw installation (9.74), and wire saw transport (3.99).

Table 11. Risk calculation results.

\begin{tabular}{|c|c|c|c|c|c|c|c|}
\hline Category & Item & \multicolumn{2}{|c|}{ Overall Score } & $\begin{array}{c}\text { Conversion } \\
\text { Weight }\end{array}$ & $\begin{array}{l}\text { Conversion } \\
\text { Value }\end{array}$ & $\begin{array}{c}\text { Dimension } \\
\text { Average Value }\end{array}$ & $\begin{array}{c}\text { Dimension } \\
\text { Ranking }\end{array}$ \\
\hline \multirow{17}{*}{$\begin{array}{l}\text { Risk assessment } \\
\text { by work type }\end{array}$} & \multirow{3}{*}{ Wire saw transport } & Collapse & 5.90 & & 3.34 & \multirow{3}{*}{3.99} & \multirow{3}{*}{4} \\
\hline & & Drop & 5.69 & 1 & 3.23 & & \\
\hline & & Jam & 9.55 & & 5.41 & & \\
\hline & \multirow{4}{*}{ Wire saw installation } & Collapse & 12.15 & \multirow{4}{*}{2} & 10.33 & \multirow{4}{*}{9.74} & \multirow{4}{*}{3} \\
\hline & & Drop & 9.34 & & 7.94 & & \\
\hline & & Jam & 17.19 & & 14.61 & & \\
\hline & & Electric shock & 7.13 & & 6.06 & & \\
\hline & \multirow{5}{*}{ Cutting using wire saw } & Collapse & 28.65 & & 29.22 & \multirow{5}{*}{21.21} & \multirow{5}{*}{2} \\
\hline & & Drop & 29.17 & & 29.75 & & \\
\hline & & Eye attack & 9.55 & 3 & 9.74 & & \\
\hline & & Jam & 29.69 & & 30.28 & & \\
\hline & & Electric shock & 6.94 & & 7.08 & & \\
\hline & \multirow{5}{*}{ Residual concrete removal } & Collapse & 34.79 & & 47.32 & \multirow{5}{*}{54.17} & \multirow{5}{*}{1} \\
\hline & & Eye attack & 49.08 & & 66.75 & & \\
\hline & & Fall & 42.71 & 4 & 58.08 & & \\
\hline & & Jam & 41.67 & & 56.67 & & \\
\hline & & Electric shock & 30.90 & & 42.03 & & \\
\hline
\end{tabular}

Table 12 presents the risk assessment results for each type of risk. The assessment results of structural risk were greater for collapse (22.55) than for drop (13.64), whereas job risks were assessed in the following order: fall (58.08), eye attack (38.25), jam (26.74), and electric shock (18.39). In the integrated assessment of structural and job risks, fall (58.08) was considered the most dangerous. The overall level of risk for job risks was high. 
Table 12. Risk calculation results by risk type.

\begin{tabular}{cccc}
\hline Category & Item & Conversion Value & Dimension Ranking \\
\hline \multirow{2}{*}{ Risk assessment by } & Collapse & 22.55 & 1 \\
structural risk & Drop & 13.64 & 2 \\
& Mean value & 18.10 & - \\
\hline \multirow{2}{*}{ Risk assessment by job risk } & Eye attack & 38.25 & 2 \\
& Fall & 58.08 & 1 \\
& Jam & 26.74 & 3 \\
& Electric shock & 18.39 & 4 \\
\hline
\end{tabular}

Table 13 presents the risk assessment results by work and risk type. The difference between the risk assessment by risk type above and that shown in Table 13 is that even for the same risk type, the assessment is divided into different items for different work stages. According to the work-risk type assessment, the total risk was evaluated as 25.17. The breakdown shows that the risk of eye attacks (66.75) and falls (58.08) in residual concrete removal were high, whereas drop (3.23) and collapse (3.34) in wire saw transport were relatively low risk activities.

Table 13. Risk assessment results by work and risk type.

\begin{tabular}{|c|c|c|c|c|}
\hline Category & Item & & Conversion Value & Dimension Ranking \\
\hline Total risk & & & 25.17 & - \\
\hline \multirow{17}{*}{ Risk assessment by risk type } & \multirow{3}{*}{ Wire saw transport } & Collapse & 3.34 & 16 \\
\hline & & Drop & 3.23 & 17 \\
\hline & & Jam & 5.41 & 15 \\
\hline & \multirow{4}{*}{ Wire saw installation } & Collapse & 10.33 & 10 \\
\hline & & Drop & 7.94 & 12 \\
\hline & & Jam & 14.61 & 9 \\
\hline & & Electric shock & 6.06 & 14 \\
\hline & \multirow{5}{*}{ Cutting using wire saw } & Collapse & 29.22 & 8 \\
\hline & & Drop & 29.75 & 7 \\
\hline & & Eye attack & 9.74 & 11 \\
\hline & & Jam & 30.28 & 6 \\
\hline & & Electric shock & 7.08 & 13 \\
\hline & \multirow{5}{*}{ Remove residual concrete } & Collapse & 47.32 & 4 \\
\hline & & Eye attack & 66.75 & 1 \\
\hline & & Fall & 58.08 & 2 \\
\hline & & Jam & 56.67 & 3 \\
\hline & & Electric shock & 42.03 & 5 \\
\hline
\end{tabular}

The risk assessment can be plotted to compare the results of all the items at a glance, as shown in Figure 3a-c. The work-specific/risk type-specific/work-risk type-specific risk assessment graphs evaluated above are analyzed as follows. 

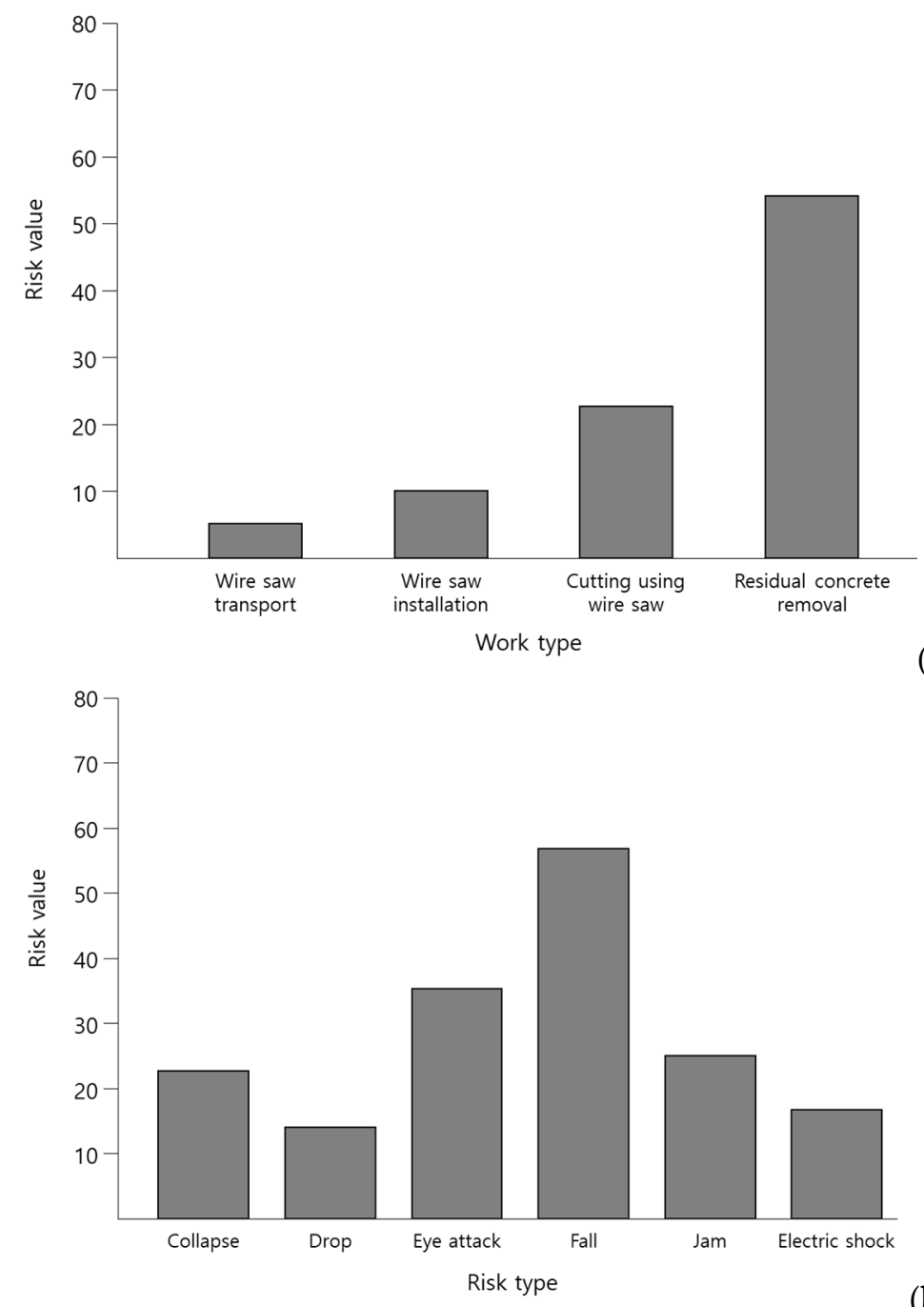

(a)

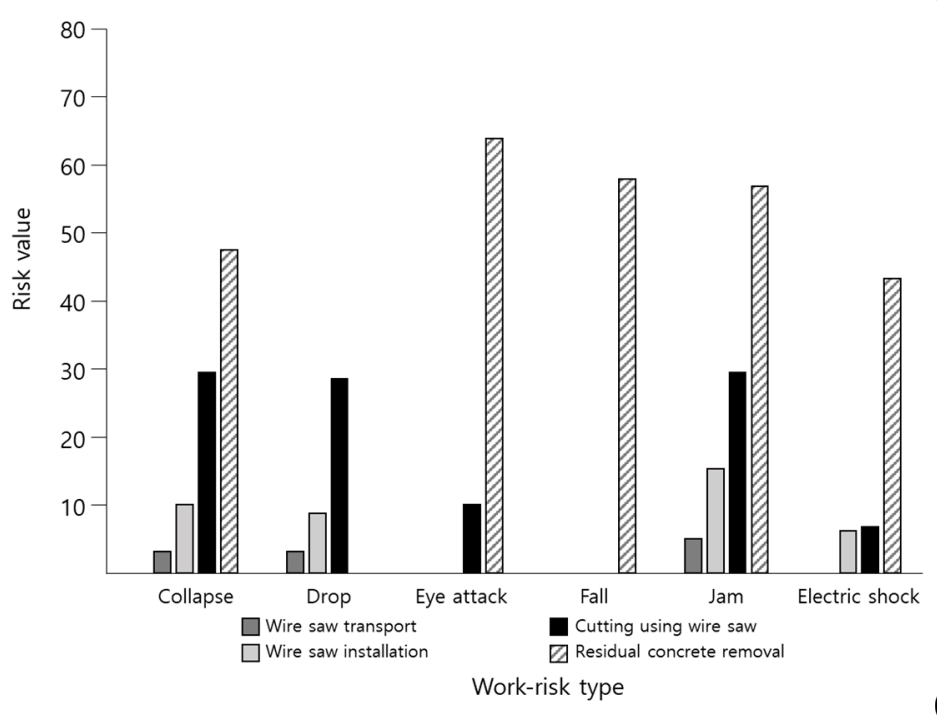

(b)

(c)

Figure 3. Comparison of risk assessment: (a) risk by work; (b) risk by risk type; (c) risk graph by risk type of work.

First, the risk assessment results by work type revealed the high level of risk involved in removing residual concrete. In particular, for remote work using machines, while the structural/job risk damage was high in absolute terms, the probability was low. In contrast, for decommissioning work directly 
performed by workers, such as removing residual concrete, while the potential damage caused varied widely for the various work processes, the frequency of occurrence was very high, and the risk was higher than when performing the work remotely using machines. This indicates that there is a need to engage in active risk management in order to prevent accidents in which workers are directly involved in carrying out tasks near the workspace, for example by strictly enforcing the use of protective equipment and mandating safety training for workers.

The expert pool assessed the risk of close-range work relatively conservatively for groups of workers working on-site compared to management groups. This was because the worker groups have limited labor input and time due to the nature of nuclear power plant decontamination and decommissioning. Therefore, the frequency of risks that workers are exposed to in close-range work is relatively high, resulting in a high-risk assessment for close-range work.

We then performed a comparative analysis of the level of risk by risk type. Within the category of structural risks, the risk of collapse was rated the highest. In particular, cutting at a high elevation must be performed for the bio-shield on a scaffold and there is thus is a high risk of collapse due to the presence of workers in such environments and the installation of equipment for the various tasks being performed, including heavy equipment [48]. However, this assessment result is limited to cutting. We expect that transport tasks performed after cutting, such as moving the cut concrete blocks, will also have a relatively high drop risk.

Among job risks, the risk of fall was the highest. When clustering risk by risk type, risk $x$ can be divided into $0<x<20$ (low), $20<x<40$ (medium), and $40<x$ (high). The low-risk group includes jams, and electric shocks, the medium-risk group includes eye attacks, and the high-risk group includes falls. These results show that the risk of falling that workers are exposed to when performing tasks on high work platforms, for example cutting concrete in the upper part of the structure, is relatively high compared to the risk of machine-related jams or electric shocks. In addition, compared to other job-related risk items, fall risk is very high due to the severe damage that can occur in falling accidents.

While the level of job and structural risks were assessed to be similar, the difference between the structural and job risks for residual concrete removal was significant, with the job risk being calculated to be higher than the structural risk. In Kori-1, the case study setting, the concrete properties, reinforcement, and similar characteristics of the structure were originally designed from a structural point of view. The shield concrete structure was built in a circular shape to reduce the risk of damage to the structure itself or neighboring temporary structures. As a result, job risk, which directly affects the worker, is higher than structural risk. Conversely, the structural risk is high when engaged in cutting operations that require the use of wire saws (Figure 4). Thus, additional active management of structural risk hazards is needed compared to other processes due to the distance between the worker and the workspace when cutting is completed.

Using the risk assessment results table (Table 13), we can compare the risks by work type and structural and job risk, as shown in Figure 4, thus allowing for more effective risk responses. In addition, by assessing the risk of various decontamination and decommissioning processes, a comparative review can be used to derive the optimal processes that can be adopted to minimize the risks for each stage of the process. In the future, the data accumulated through additional expert interviews and case studies can be incorporated into this analysis to improve the proposed model's utilization and reliability. 


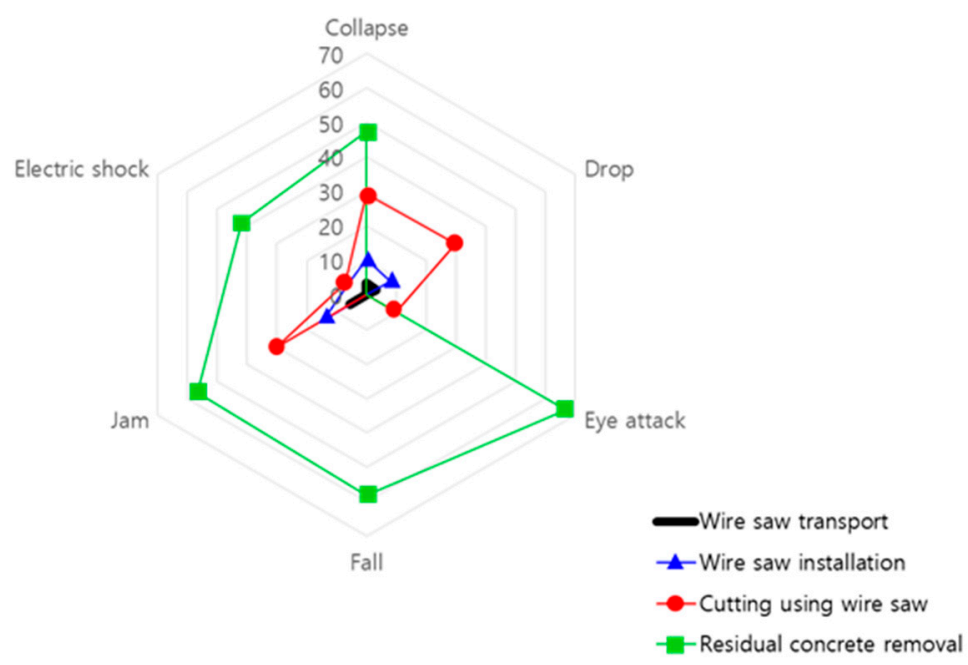

Figure 4. Integrated risk graph by work type.

\section{Sensitivity Analysis}

The fuzzy-based structural/job risk assessment method developed in this study for the decommissioning process of nuclear power plants needs to be verified. Here, the sensitivity analysis was performed by changing each of the variables in turn to values that were $\pm 100 \%$ of those originally assigned. This will demonstrate that the model is relatively robust if the ranking is not reversed by changing the variables so dramatically. The results of this sensitivity analysis confirmed that the outcome values did not change significantly depending on the external environment, and that the evaluation method itself is therefore robust.

The sensitivity analysis conducted for the risk assessment of cutting work carried out on the concrete structure of the nuclear power plant confirmed that the ranking of the risk assessment was not reversed despite the major change in the value of the input variables, as shown in Figure 5; Figure 6 shows that the ranking of risk assessment by risk type was also not reversed. The risk type designations used in these two figures is as shown in Table 14, which shows the results of the sensitivity analysis performed on the cutting work for the risk associated with each type of work. For example, as the data presented in Table 14 shows, the original risk result for A1 (wire saw transport-collapse) was 3.34 , changing to 12.40 and 0.69 when two of the input variables, namely frequency and intensity, respectively, changed.

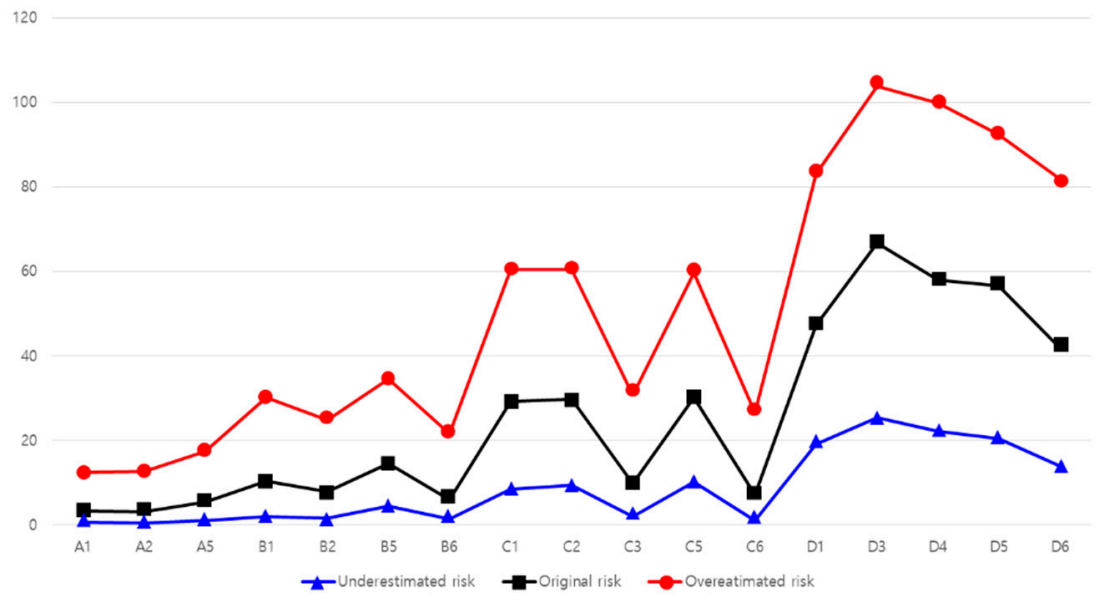

Figure 5. Sensitivity analysis on structural/job risks by work-risk type. 


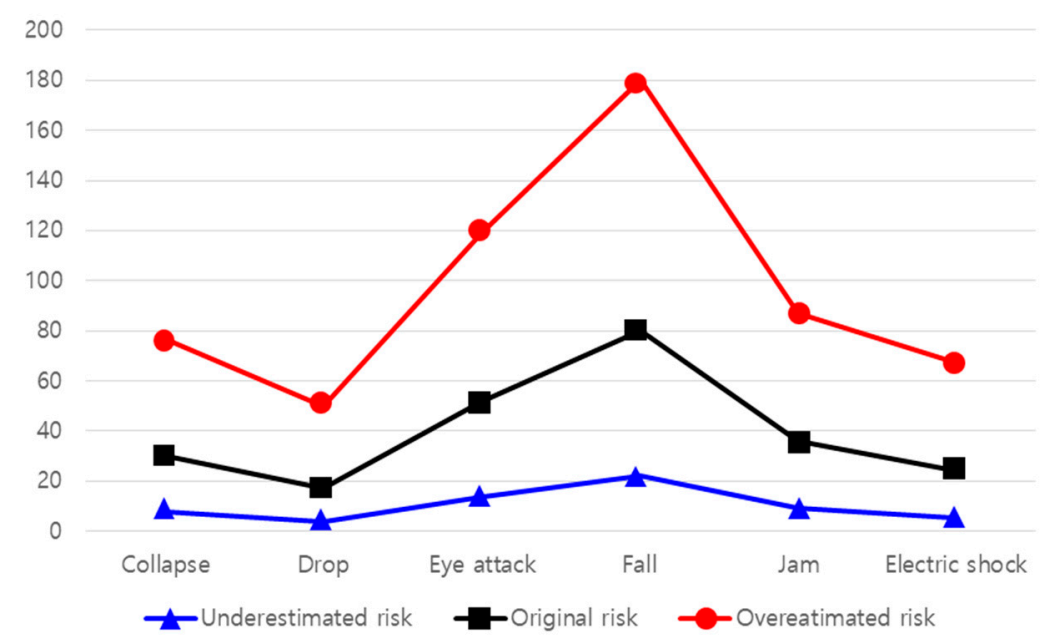

Figure 6. Sensitivity analysis on structural/job risks by risk type.

Table 14. Results of sensitivity analysis on structural/job risks.

\begin{tabular}{|c|c|c|c|c|}
\hline \multirow{2}{*}{\multicolumn{2}{|c|}{ Type ${ }^{a}$}} & \multicolumn{3}{|c|}{ Structural/Job Risk } \\
\hline & & \multirow{2}{*}{$\begin{array}{c}\text { Underestimated Risk } \\
-\end{array}$} & \multirow{2}{*}{$\begin{array}{c}\text { Original Risk } \\
-\end{array}$} & \multirow{2}{*}{$\begin{array}{c}\text { Overestimated Risk } \\
-\end{array}$} \\
\hline & Work-risk type & & & \\
\hline $\mathrm{A} 1$ & Collapse & 0.69 & 3.34 & 12.40 \\
\hline A2 & Drop & 0.53 & 3.23 & 12.69 \\
\hline A5 & Jam & 1.00 & 5.41 & 17.41 \\
\hline B1 & Collapse & 2.07 & 10.33 & 30.10 \\
\hline B2 & Drop & 1.56 & 7.94 & 24.79 \\
\hline B5 & Jam & 4.57 & 14.61 & 34.53 \\
\hline B6 & Electric shock & 1.42 & 6.08 & 21.69 \\
\hline $\mathrm{C} 1$ & Collapse & 8.57 & 29.22 & 60.56 \\
\hline $\mathrm{C} 2$ & Drop & 9.35 & 29.75 & 60.56 \\
\hline C3 & Eye attack & 1.95 & 9.74 & 30.81 \\
\hline C5 & Jam & 10.20 & 30.28 & 59.68 \\
\hline C6 & Electric shock & 1.10 & 7.08 & 26.56 \\
\hline D1 & Collapse & 19.17 & 47.32 & 83.11 \\
\hline D3 & Eye attack & 25.50 & 66.75 & 103.89 \\
\hline D4 & Fall & 22.24 & 58.08 & 99.88 \\
\hline D5 & Jam & 20.54 & 56.67 & 92.56 \\
\hline D6 & Electric shock & 14.03 & 42.03 & 81.93 \\
\hline & Work type & - & - & - \\
\hline A & Wire saw transport & 0.74 & 3.99 & 14.17 \\
\hline B & Wire saw installation & 2.41 & 9.74 & 27.78 \\
\hline $\mathrm{C}$ & Cutting using wire saw & 6.23 & 21.21 & 47.64 \\
\hline $\mathrm{D}$ & Remove residual concrete & 20.30 & 54.17 & 92.27 \\
\hline & Risk type & - & - & - \\
\hline 1 & Collapse & 7.62 & 22.55 & 46.54 \\
\hline 2 & Drop & 3.82 & 13.64 & 32.68 \\
\hline 3 & Eye attack & 13.72 & 38.25 & 67.35 \\
\hline 4 & Fall & 22.24 & 58.08 & 99.88 \\
\hline 5 & Jam & 9.08 & 26.74 & 51.04 \\
\hline 6 & Electric shock & 5.51 & 18.40 & 43.40 \\
\hline
\end{tabular}

${ }^{a} \mathrm{~A}=$ wire saw transport; $\mathrm{B}=$ wire saw installation; $\mathrm{C}=$ cutting using wire saw; $\mathrm{D}=$ remove residual concrete. $1=$ collapse $2=$ drop; $3=$ eye attack; $4=$ fall $; 5=$ jam; $6=$ electric shock.

Based on the results of the sensitivity analysis, the method for assessing the risk of the decommissioning process proposed in this study is considered to be a robust method. When looking at the risk assessment results for the concrete structure cutting work, the structural/job risk was the highest for 'remove residual concrete', followed by 'cutting using wire saw', 'wire saw installation' and 'wire saw transport'. 
For each work phase, the risk was evaluated as high for the work types where the worker is expected to work on the decommissioning object at close range. As a result of the application of the model to the expected decommissioning scenario, the risks of detailed work on the target were quantitatively assessed and found to be comparable to those actually experienced, and the results of the risk assessment are readily identified in the program, making it easier to judge.

As the structural and job risk assessment method proposed for the decommissioning of nuclear power plants in this study was the first to be attempted, either domestically or internationally, it was difficult to compare its performance directly with others because there was no previous method to refer to. Sensitivity analyses were performed to demonstrate that the assessment method presented is robust and that the outcome values are not easily changed depending on the external environment. As a result, the proposed method for assessing structural and job risk in the decommissioning work of nuclear facilities was found to be not sensitive to changes in the fuzzy membership function of the input variables.

\section{Conclusions and Discussion}

In this study, we proposed a framework that can quantitatively present subjective judgments or evaluations of ambiguous and qualitative experts about the safe degree of decommissioning work of bio-shield structure in nuclear power plant. First of all, we derived the risks for each decontamination and decommissioning process via the matching process based on the construction industry hazard profile and the decontamination and decommissioning processes. Subsequently, an assessment model was developed and the safety performance of risks elicited was conducted measurement.

Existing risk assessments for the decontamination and decommissioning of nuclear facilities have generally focused on the radiological factors involved. In addition, if risk scores must be consolidated based on an unclear correlation between radiological, non-radiological, and structural risks, there is a limitation that it becomes far more difficult to control the consolidation method for each factor or any fluctuations in the risk score after consolidation. This paper highlights the problems caused by these existing deterministic risk assessment methods and suggests a risk assessment methodology that incorporates fuzzy functions as a viable alternative approach. The following results were obtained through the risk assessment case study of cutting work performed as part of the decontamination and decommissioning of the Kori-1 nuclear power plant by applying the proposed assessment methodology.

First, using the fuzzy analysis model, we proposed a methodology in which the function is configured so that the assessor can respond to a range of risks even while knowing only the approximate opinion of the nuclear power plant decontamination and decommissioning experts rather than precise information, thereby enabling the assessor to develop a better understanding of the important decision-making characteristics.

Second, we classified the risks for each process in terms of work type, structural risk, and job risk, and developed a risk classification system that analyzes and compares alternatives through a multidimensional approach. While the previous deterministic studies were difficult to reflect the structural characteristics of each bio-shield structure in a uniform risk assessment method, the risk assessment model developed in this study reflects the characteristics of nuclear power plant decontamination and dismantling work, so it is possible to assess the risks according to the situation.

Third, we proposed a fuzzy number weighted average analysis model, which was then employed to develop a methodology to relatively assess risks that are difficult to compare directly. Existing risk assessment methods have limitations in establishing a specific safety plan because there is no distinction between detailed tasks. On the other hand, the risk assessment method developed in this study is based on suggesting strategies such as safety behavior rules through analysis of changes in relative risk when applying alternatives.

The fuzzy based risk assessment model proposed in this study can reduce the risk of prediction failure compared to the results of the existing deterministic risk assessment model. This will enable personnel to assess various risks of decontamination and decommissioning work of nuclear power plant 
structures that cannot be quantitatively assessed owing to the lack of data. Further, the proposed fuzzy based risk assessment model can be extended to cover risk assessment exercises in other engineering fields that are dependent on the judgment of experts and also suffer from a lack of available statistical data and the difficultly of relatively assessing factors.

In future work, we plan to move on to develop an overall risk assessment process and step-by-step comparative analysis model for decontamination and decommissioning by extending the risk assessment to the pre- and post-operation phases of cutting based on the proposed fuzzy based risk assessment model. In addition, we plan to expand the verification pool to include experts who have experienced advanced cases of nuclear facility decommissioning, and we will also conduct case studies of nuclear facility decommissioning abroad to develop a risk assessment model based on global standards.

Author Contributions: Conceptualization, B.K. and J.s.L.; methodology, B.K. and J.s.L.; validation, B.K., J.s.L. and Y.h.A.; investigation, J.s.L. and Y.h.A.; writing—original draft preparation, B.K.; writing—review and editing, J.s.L. and Y.h.A.; visualization, B.K.; supervision, J.s.L.; project administration, Y.h.A. All authors have read and agreed to the published version of the manuscript.

Funding: This work was supported by the Korean Institute of Energy Technology Evaluation and Planning (KETEP) and the Ministry of Trade, Industry \& Energy (MOTIE) of the Republic of Korea (No. 20161510300420).

Conflicts of Interest: The authors declare no conflict of interest.

\section{References}

1. Reisenweaver, D.W. Status of the Decommissioning of Nuclear Facilities around the World. Intl. Atomic Energy Agency 2004.

2. Jeong, K.S.; Lee, K.W.; Lim, H.K. Risk assessment on hazards for decommissioning safety of a nuclear facility. Ann. Nucl. Energy 2010, 37, 1751-1762. [CrossRef]

3. International Atomic Energy Agency (IAEA). Decommissioning of Nuclear Power Plants and Research Reactors; IAEA Safety Standards Series No. WS-G-2.1; International Atomic Energy Agency: Vienna, Austria, 1999.

4. International Atomic Energy Agency (IAEA). Decommissioning of Facilities using Radioactive Material; IAEA Safety Standards Series No. WS-R-5; International Atomic Energy Agency (IAEA): Vienna, Austria, 2006.

5. Suh, Y.A.; Hornigrook, C.; Yim, M.S. Decisions on nuclear decommissioning strategies: Historical review. Prog. Nucl. Energy. 2018, 106, 34-43. [CrossRef]

6. Findley, M.; Smith, S.; Gorski, J.; O'Neil, M. Safety climate differences among job positions in a nuclear decommissioning and demolition industry: Employees' self-reported safety attitudes and perceptions. Saf. Sci. 2007, 45, 875-889. [CrossRef]

7. Yazdani-Chamzini, A. Proposing a new methodology based on fuzzy logic for tunnelling risk assessment. J. Civ. Eng. Manag. 2014, 20, 82-94. [CrossRef]

8. Han, M.H.; Lee, Y.B.; Kim, E.H.; Suh, K.S.; Hwang, W.T. Development of a Real-Time Radiological Dose Assessment System (No. KAERI/RR—1667/96); Korea Atomic Energy Research Institute: Daejeon, Korea, 1997.

9. United States Department of Energy (DOE). Statistical Evaluation of DOE DED Occurrences DOE/EH-0578; United States Department of Energy (DOE): Washington, DC, USA, 1998.

10. Zadeh, L.A. Fuzzy sets. Inf. Control. 1965, 8, 338-353. [CrossRef]

11. Kang, D.G.; Ahn, S.H.; Chang, S.H. A combined deterministic and probabilistic procedure for safety assessment of beyond design basis accidents in nuclear power plant: Application to ECCS performance assessment for design basis LOCA redefinition. Nucl. Eng. Des. 2013, 260, 165-174. [CrossRef]

12. Boyack, B.; Duffey, R.; Wilson, G.; Griffith, P.; Lellouche, G.; Levy, S.; Rohatgi, U.; Wulff, W.; Zuber, N. Quantifying Reactor Safety Margins-Application of Code Scaling, Applicability, and Uncertainty Evaluation Methodology to a Large-Break, Loss-of-Coolant Accident (NUREG/CR-5249). Nuclear Regulatory Commission. 1989.

13. Liu, P.; Wu, Y.C. Fault tree analysis strategy for living PSA. Nucl. Power Eng. Chin. 2003, 24, 568-572.

14. Liu, P.; Wu, Y.; Li, Y.; Wang, H.; Hu, L.; Zhang, S.; Ma, X.; Nie, M.; Yuan, R. An ordering scheme of the basic events based on zero-suppressed binary decision diagrams for the large-scale fault tree analysis. Chin. J. Nucl. Sci. Eng. 2007, 27, 282-288. 
15. Wang, H.T.; Wu, Y.C.; Li, Y.Z. Software development for risk monitor in nuclear power plants. Nucl. Power Eng. Chin. 2009, 30, 26-30.

16. Nuclear Regulatory Commission (NRC). Reactor Safety Study; WASH-1400; Nuclear Regulatory Commission (NRC): Washington, DC, USA, 1975; Volume 75.

17. Wang, H.T.; Wu, Y.C.; Ding, H. Algorithms of consequence analysis for PSA in nuclear power plant. Energy Sci. Technol. Chin. 2008, 42, 724-728.

18. Yuan, R.; Li, Y.Z.; Hu, L.Q.; Wang, H.; Wu, Y.; Gao, F. Development of import module for event trees in RiskA. Chin. J. Nucl. Sci. Eng. 2008, 28, 176-179.

19. Sousa, L.R.; Einstein, H.H. Risk analysis during tunnel construction using Bayesian Networks: Porto Metro case study. Tunn. Undergr. Space Technol. 2012, 27, 86-100. [CrossRef]

20. Špačková, O.; Straub, D. Dynamic Bayesian network for probabilistic modeling of tunnel excavation processes. Comput. Aided Civ. Infrastruct. Eng. 2013, 28, 1-21.

21. Wu, J.; Fang, W.; Hu, Z.; Hong, B. Application of bayesian approach to dynamic assessment of flood in urban underground spaces. Water 2018, 10, 1112. [CrossRef]

22. Beynon, M.; Cosker, D.; Marshall, D. An expert system for multi-criteria decision making using Dempster Shafer theory. Expert Syst. Appl. 2001, 20, 357-367. [CrossRef]

23. Haenni, R. Are alternatives to Dempster's rule of combination real alternatives? Comments on "About the belief function combination and the conflict management problem"-Lefevre et al. Inf. Fusion. 2002, 3, 237-239. [CrossRef]

24. Li, B.; Pang, F.W. An approach of vessel collision risk assessment based on the D-S evidence theory. Ocean Eng. 2013, 74, 16-21. [CrossRef]

25. Zhang, L.; Ding, L.; Wu, X.; Skibniewski, M.J. An improved Dempster-Shafer approach to construction safety risk perception. Knowl. Based Syst. 2017, 132, 30-46. [CrossRef]

26. Bezdek, J.C. Pattern Recognition with Fuzzy Objective Function Algorithm; Springer Science \& Business Media: Dordrecht, The Netherlands, 2013.

27. Deng, X.; Xu, Y.; Han, L.; Yu, Z.; Yang, M.; Pan, G. Assessment of river health based on an improved entropy-based fuzzy matter-element model in the Taihu Plain, China. Ecol. Indic. 2015, 57, 85-95. [CrossRef]

28. Kim, B.; Lee, J.S.; Ahn, Y.H. Development of risk breakdown structure of nuclear power plant decommissioning project: Focusing on structural damage/work process risks. J. Kor. Inst. Struct. Maint. Insp. 2018, 22, $38-45$.

29. Occupational Safety and Health Administration (OSHA). Worker Safety Series: Construction Pocket Guide; OSHA 3252-05N; Occupational Safety and Health Administration (OSHA): Washington, DC, USA, 2005.

30. International Atomic Energy Agency (IAEA). Safety Assessment for the Decommissioning of Facilities Using Radioactive Material; IAEA Safety Standards Series No. WS-G-5.2; International Atomic Energy Agency (IAEA): Vienna, Austria, 2008.

31. Babilas, E.; Uspuras, E.; Rimkevicius, S.; Dundulis, G.; Vaisnoras, M. Safety Assessment of Low-Contaminated Equipment Dismantling at Nuclear Power Plants. Sci. Technol. Nucl. Install. 2015, 1-11. [CrossRef]

32. Ahmadi, M.; Behzadian, K.; Ardeshir, A.; Kapelan, Z. Comprehensive risk management using fuzzy FMEA and MCDA techniques in highway construction projects. J. Civ. Eng. Manag. 2017, 23, 300-310. [CrossRef]

33. Mohandes, S.R.; Zhang, X. Towards the development of a comprehensive hybrid fuzzy-based occupational risk assessment model for construction workers. Saf. Sci. 2019, 115, 294-309. [CrossRef]

34. Liu, J.; Yang, J.-B.; Wang, J.; Sii, H.-S.; Wang, Y. Fuzzy rule-based evidential reasoning approach for safety analysis. Int. J. Gen. Syst. 2004, 33, 183-204. [CrossRef]

35. Kim, J.H.; Yoo, W.S.; Cho, H.H.; Kang, K.I. Fuzzy-Based Approach for Assessing Safety Performance of Tower Crane Operation on Construction Sites. In Proceedings of the Architectural Institute of Korea Structure $\mathcal{E}$ Construction; Architectural Institute of Korea: Seoul, Korea, 2009; pp. 737-740.

36. Faber, M.H.; Stewart, M.G. Risk assessment for civil engineering facilities: Critical overview and discussion. Reliab. Eng. Syst. Safe. 2003, 80, 173-184. [CrossRef]

37. Nilsen, T.; Aven, T. Models and model uncertainty in the context of risk analysis. Reliab. Eng. Sys. Safe. 2003, 79, 309-317. [CrossRef]

38. Lim, H.K.; Kim, H.J. Comprehensive assessment on risk factors using fuzzy inference in decommissioning process. J. Kor. Soc. Safe. 2014, 29, 184-190. [CrossRef] 
39. Azadeh, A.; Fam, I.M.; Khoshnoud, M.; Nikafrouz, M. Design and implementation of a fuzzy expert system for performance assessment of an integrated health, safety, environment (HSE) and ergonomics system: The case of a gas refinery. Inf. Sci. 2008, 178, 4280-4300. [CrossRef]

40. Lee, S.; Halpin, D.W. Predictive tool for estimating accident risk. J. Constr. Eng. Manag. 2003, 129, $431-436$. [CrossRef]

41. Department of Defense (DOD). MIL-STD-882D System Safety Program Requirements; Standard Practice for System Safety; Department of Defense (DOD): Washington, DC, USA, 2000.

42. Heldman, K.; Baca, C.; Jansen, P. PMP: Project Management Professional Exam Study Guide; John Wiley \& Sons: Hoboken, NJ, USA, 2007.

43. Hallowell, M.R.; Yugar-Arias, I.F. Exploring fundamental causes of safety challenges faced by Hispanic construction workers in the US using photovoice. Saf. Sci. 2016, 82, 199-211. [CrossRef]

44. Health and Safety Executive (HSE). Kinds of Accident Statistics in Great Britain; Health and Safety Executive (HSE): London, UK, 2018.

45. Granhed, H.; Altgärde, E.; Akyürek, L.M.; David, P. Injuries Sustained by Falls-A Review. Trauma Acute Care 2017, 2.

46. McBride, M. Disability Evaluation and Principles of Treatment of Compensable Injuries, 6th ed.; Lippincott Company: Philadelphia, PA, USA, 1963; pp. 68-103.

47. Sivanandam, S.N.; Sumathi, S.; Deepa, S.N. Introduction to Fuzzy Logic Using MATLAB; Springer: Berlin, Germany, 2006.

48. Li, F.; Zeng, J.; Huang, J.; Zhang, J.; Chen, Y.; Yan, H.; Huang, W.; Lu, X.; Yip, P.S. Work-related and non-work-related accident fatal falls in Shanghai and Wuhan, China. Saf. Sci. 2019, 117, 43-48. [CrossRef]

(C) 2020 by the authors. Licensee MDPI, Basel, Switzerland. This article is an open access article distributed under the terms and conditions of the Creative Commons Attribution (CC BY) license (http://creativecommons.org/licenses/by/4.0/). 